stitutional symptoms are profound. (2) A fatal condition such as lymphadenoma or tuberculous meningitis should never be finally diagnosed, even though strongly suspected, unless there is irrefutable proof. (3) It is always tempting to regard as tuberculous a persistent pyrexia for which no cause can be found, and so to make a diagnosis of probability on quite inadequate evidence. Tuberculosis is often the cause of long continued fever but is very rarely the cause of unexplained long continued fever. It is just as blameworthy to label a patient as tuberculous when no such infection is, in fact, present, as to fail to diagnose tuberculosis when it is present.

I wish to thank Dr. R. Coope for his help in the writing of this article.

\section{BIBLIOGRAPHY}

ALT and BARKER (1930), F. Am. Med. Assoc., 94, 1457. HARRIS (1946), F. Am. Med. Assoc., r31, 1485.

KILHAM and STEIGMAN (1942), The Lancet, 2, 452.

KINTNER and ROWNTREE (r934), f. Am. Med. Ass., ro2, 889.

\title{
THE PRINCIPLES UNDERLYING THE ARTIFICIAL FEEDING OF INFANTS
}

\author{
By Malcolm MacGregor, M.D., M.R.C.P., D.C.H. \\ Ex-Service Specialist in Paediatrics at St. Mary's Hospital
}

An apology, or at least an explanation, may be thought to be called for before adding to the already too considerable mass of print on the subject of infant feeding. This article can claim no originality, but its aim is to focus attention upon the facts which lie behind the current systems of artificial feeding of infants, and to leave aside their practical details, lucidly and elaborately expounded by other authors.

That it is desirable to feed infants at the breast is no new discovery. Until recent years the feeding of infants by breast milk substitutes was fraught with such hazards that it was little employed, and human milk from a wet-nurse almost invariably used instead.

\section{' Fling off the useless and corrupted fuice}

And teach the child the Nipple's frequent use.'

is an 18th century expression of an attitude to artificial feeding more extreme than prevails in our own time. The reasons for the failure in olden days of other modes than breast feeding are not far to seek. There was no appreciation of the organismal dangers of fresh cow's milk, and efforts to dispense with milk altogether as, for example, this German one of 1632 ,

'In our parts infants are given with good result broth made of beer mixed with boiled bread and butter, which is quite nourishing. Wine should not be given to infants, but in our parts beer is given to them with advantage.'

however well-suited to 'our parts,' do not seem to modern ears to contain a germ of universal applicability. Furthermore, there was considerable opportunity for contamination of the infant's food during and after preparation, if we may judge from the following example, translated from a 16 th century treatise :-

'With milk and bread the sooty tin they fill Stir it together o'er the Fire and boil,

Then try it with a touch, the Spoon they dip

Blow it, and put it to his craving lip.'

In short, although scattered examples in Europe of successful infant feeding with cow's milk exist from the 18th century onwards, wet-nurses were of far greater importance and required careful selection,

' Let the infant have a nurse from 25-35 years old, who is of ruddy complexion or not far from it, a moderate meat-eater also, not inclined to drunkenness but of good morals and not exercising sexual intercourse.'

for serious consequences.might follow a bad choice; thus

' Oft at a Venal Pap they suck their Bane And in their blood the latent Plague retain.' or again,

'If bad the milk the Manners may be loose.'

More recently artificial feeding, that is the feeding of infants with material other than human milk, has been of two principal types :-

I. The use of the milk of other animals, especially the cow, though goat, ass and mare have also 
been used for the purpose. It is usual to withdraw the milk and to offer it to the infant, raw or modified, at a later time, but the method of placing the infant direct to the udder has enjoyed popularity as, for example, in Paris as late as the end of the last century. We read that 'the results (from other methods) were, however, so poor that after 1881 only asses were used in this manner. With these the results were so much better that the bottle was completely abolished from the maternity hospital in Paris. A stable for asses was established in close conjunction with the Pavillion Parrot, with a covered passage-way between.' 'Today (according to Brennerman) direct nursing is practically restricted to the goat in certain countries, as a local custom rather than for therapeutic purposes.

2. The use of milk substitutes. This method has received stimulus from periods of milk shortage, such as the past few years, but apart from the obvious indications of sensitivity to cow's milk preparations, or scarcity of them, the method has received little attention in this country. Formulae which approach the composition of milk in their protein, carbohydrate and fat contents, may be constructed with alien ingredients such as soya bean flour, olive oil and starch, and on such formulae infants may be successfully reared, but some doubt about the extent to which essential constituents are absorbed has restrained paediatricians from adopting such formulae when definite indications are absent. Protein digests such as casein hydrolysate, although usually milk derivatives, may be mentioned here as an auxiliary means of infant feeding, with the advantage that they may be administered parenterally, but in the feeding of healthy full-term infants they have no place at the present time.

Modern methods of artificial feeding employ cow's milk almost exclusively. To study what this involves to the infant, we must consider first the alimentary equipment of the infant and, second, in what respects cow's milk differs from the infant's natural food.

\section{The Digestive Apparatus of the Infant}

In small babies the area of absorptive and secretory epithelium in the alimentary tract is greater in proportion to the supporting tissues than is the case in adults. From the later months of intra-uterine life adequate enzymes for. all simple foods are available, with the exception of pancreatic amylase which is deficient for the first few post-natal months. Gastric hydrochloric acid decreases from a high neonatal level to a low figure during the first half of the first year of life. In short, the infant possesses the means to digest and absorb all ordinary foodstuffs, and the structure of its intestine would seem to facilitate absorption; the gastric acidity is low, howeverơ and complex carbohydrates cannot be dealt wit immediately. Nevertheless in the second half of the first year of life there is no sharp dividing line between the digestive powers of the infant an $\overrightarrow{f_{5}}$ those of the adult.

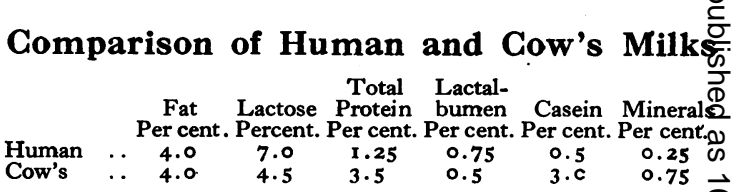

Physiologically, the difference between the milks is more profound than appears from the్ above table; indeed, for reasons that are nos wholly clear, even chemically identical substances? do not seem to be utilized equally in the two milks Let us consider the components singly.

I. Protein. Besides the greater total quantityo of protein in cow's milk, the enormous relative $\varepsilon_{\infty}^{\infty}$ preponderance of casein in the latter should be noted.

Lactalbumen is known to vary in composition slightly from species to species, but there is now convincing evidence that cow's lactalbumen is un- 들 suitable for human infants, except in the rarew individuals who react allergically to it. Lactal bumen is coagulable by heating, but does not chote in the stomach.

The casein appears to be of the same composition in both milks. Striking differences in thes behaviour of the two milks are observed, however when they enter the stomach. Both milks ' curdle in contact with gastric juice. Breast milk pro-市 duces very small, soft curds, separable with difficulty from the fluid ' whey.' The behaviouro of raw cow's milk is very different ; it enters the stomach a liquid and there becomes a very solid food. Small curds form at first, but these curds possess to a high degree the property of adhesion. 3 . Numerous curds coalesce at their lines of contact: within a few minutes, and as a result a series of 3 . firm, walnut-sized chunks are formed, which are mechanically irritating, unapproachable by en-₹ zymes, and in many cases too large to pass theo pylorus, or even to be vomited. ("And the crude Burthen undigested lyes.') In fact, it would ap-으․ pear that cow's milk is designed to accustom the calf to the early use of coarse solid food. The largeo aggregates of casein contract with time, but are $N$ capable of only surface digestion, as enzymes are unable to penetrate their dense structure. Thiso property of cow's milk is a potent cause of digestive upset if raw cow's milk is employed for $\frac{\sim}{\mathbb{D}}$ human infants, but provided that the curd size $\stackrel{\infty}{+}$ can be reduced to that of breast milk, cow's milk 0 protein seems as well assimilated as human pro- 0 tein, but is necessary in slightly larger relative 
amount. For this reason formulae which attempt by reducing the protein to 2 per cent. or lower to ' humanize' cow's milk, succeed less well than other modes of modifying cow's milk which preserve a higher protein content. Protein indigestion is very rare; the excess of protein may be desirable on account of the more lactalbumen which is thereby supplied. Moreover, there appears to be an antagonism in the infant gut between the activities of the putrefactive bacteria (assisted by protein excess) and those of fermentation (assisted by carbohydrate excess). Whereas in the breast-fed baby fermentation is usually dominant, such dominance in the artificially-fed baby is found to produce in many cases a fermentative diarrhoea. This fact, though unexplained, provides another reason for retaining, where possible, a higher protein than would seem physiological.

2. Fat. Fat is the most variable element in both human and cow's milk ; in Jersey milk it is present up to 5 per cent. and more, while in some other milks its proportion may be very low. There is, in cow's milk, more palmitin and stearin, and less olein than in breast milk; more volatile fatty acids which it is possible may be irritating to the gastro-intestinal tract. The globules of fat in the cow's milk emulsion are larger in size, but it is doubtful if this has any clinical bearing as homogenization which reduces globule size to tiny units seems to make little difference. Finally, there is 'greater delay in stomach emptying after a cow's milk feed than after breast milk, and this is related directly to the fat content. None of these observed differences sufficiently explain the undoubted fact that fat is the element in cow's milk most difficult for the infant to utilize. The low fat content of colostrum suggests that during the neonatal period the demand for fat is low, in spite of an adequate provision of intestinal lipolytic enzymes, and it is certain that digestive upsets in infants may be ascribed more often to fat intolerance than to disturbance from other elements in the diet. This infirmity in fat utilization is especially notable after infections.

3. Carbohydrate. This element is essential to the infant, and is present in human milk in considerably higher proportion than in cow's milk. As to the choice of carbohydrate, it is generally accepted that lactose has no advantage to the infant over dextrose or sucrose. The breast-fed baby taking $40 \mathrm{oz}$. of milk (which is the upper limit of supply) receives therein $3 \mathrm{oz}$. of sugar daily. Logically, therefore, this amount should be the maximum in artificial feeding, and it is more than is available from present-day rations. It is possible to feed certain infants on considerably higher carbohydrate intakes ( 17 per cent. or more in feeds) without ill-effects, but increasing the sugar raises the liability to fermentative diarrhoea, besides accustoming the infant to a syrupy solution, a taste that he may be unwilling to relinquish later. In order to lessen the tendency of sugar to cause diarrhoea, a mixture of dextrins and maltose is frequently used instead, especially during and after digestive upsets. These substances are intermediate products in the breakdown of starch to glucose, and it is claimed that they are so slowly broken down in the intestine to glucose, that it is absorbed as rapidly as it is formed, without time for fermentation to take place. Also, dextrins are scarcely sweet to the taste. Although these claims for dextri-maltose are not universally endorsed, it is increasingly popular as a sugar substitute.

We have seen that amylase is deficient in the infant gut in the early months, and it has been customary to withhold starch from the diet until about the sixth month. However, the trend is now towards the earlier introduction of starch (from the third month) as it is clear that no great difficulty is experienced in assimilating this element, from the way in which small babies can thrive on feeds thickened with cereals in the treatment of vomiting. There is some virtue inherent in starch which is not found in the simpler carbohydrates, which makes it the most useful supplement when milk feeds will no longer suffice alone.

4. Minerals. In raw cow's milk all mineral elements except iron are present in greater quantity than in human milk. This appears to be of no practical significance, as the excess is rapidly excreted. In dilutions of cow's milk the calcium may, however, become reduced below the threshold requirement, besides still further reducing the iron content. Many proprietary milk modifications are fortified with iron before being put on the market, but the potential deficiency in iron of all artificially fed infants should be remembered.

5. Vitamins. While the supplies of vitamin B are generally regarded as sufficiently liberal in both human and cow's milk to satisfy the infant's needs, the same is not the case with $A, C$ and D. The content of vitamin $C$ is very variable, depending on seasonal and other factors (such as the protein modifying process) and cannot be relied upon to be sufficient. Vitamins A and D likewise are variable in quantity and generally inadequate, especially in the low-fat modifications of cow's milk. Supplements, therefore, of A, C and D are essential during the early months.

\section{Glinical Application}

The story of artificial feeding is that of the attempt to modify cow's milk so as to produce a food on which infants do as well as on the breast. 
Complete success has not been achieved, but the normal baby will flourish on reasonable artificial feeding. The subject has suffered until recently from an excess of dogmatism and an insufficiency of data; there have been no sound premises by reference to which doctrinaire attitudes could be gainsaid. It must be recognized that madern practice has tended to be over-precise ; the laws of infant feeding to be more rigid than those the infant's physiology obeys. The latitude which the make-up of the normal infant will allow accounts for the equal success of apparently conflicting systems, while enthusiasm and devotion are important ingredients in a feeding programme which are often overlooked in assessing its results.

'Reasoning alone can never be the foundation of medicinal precepts,' and this is nowhere truer than in the realm under discussion.

'Let us consider what Nature directs in the case; if we follow Nature, instead of leading or driving it, we cannot err. In the business of Nursing, as well as Physic, Art is ever destructive if it does not exactly copy this original.' Although we cannot swallow this last assertion as it stands, we may, in the spirit of William Cadogan's advice, announce some empirical laws for guidance in artificial feeding, in the light of what has already been said.

(a) The protein in cow's milk must be modified in some way before administration.

(b) The fat must be reduced in quantity, especially during the neonatal period.

(c) Carbohydrate must be added in order to satisfy the larger sugar requirement of the human infant.

(d) Cow's milk cannot be slavishly ' humanized' with success; aim rather at converting the human infant into a calf, as far as tolerating supernormal amounts of protein is concerned.

(e) Additional vitamins A, C and D are necessary for the artificially fed baby.

\section{The Modification of Protein}

This can be achieved in many ways so that the curd approximates to that of breast milk.

I. Dilution with water. However, to be effective, the milk must be watered to six times its volume, and this reduces the energy content to a low figure.

2. Boiling. The size and density of the curd are reduced by this means in proportion to the length of heating. Lactalbumen is coagulated.

3. Alkaliniation, with lime water, citrate or bicarbonate, will somewhat reduce the density of the curd.

4. Precoagulation with rennin, or predigestion (' peptoniation') are successful but old-fashioned and laborious methods.
5. Acidification.
(a) Naturally soured milk.

Buttermilk, the end-product of removing buttẽ.; from naturally soured cream, contains protein a form modified by bacterial action and a reduced content of fat, so is theoretically most acceptable, but in fact the lowered fat content seems to cor fer no advantage over other forms of acid mit which will compensate for the added difficulty procuring it.

(b) The adding of lactic acid to boiled cow milk will provide a product as satisfactory as bacterially soured milk, and so, being more easify controlled, is to be preferred. To prepare it the milk must be cold, the addition must be made immediately before the feed, very slowly wit constant agitation. Acid milks, besides providin a fine protein curd, reduce the power of cow's mil to neutralize gastric $\mathrm{HCl}$, which depends on thin 'buffer action' of the high mineral content. Acid milks are well assimilated, even undiluted, but tho taste is often objectionable to the older infanie They are available also in dried form.

6. Drying. This is accomplished commercially either by passing cow's milk over steam-heatech rollers, or by injecting it in the form of a spray high pressure into a vacuum chamber, and coE lecting the solid residue. The first process is more usual and cheaper. The fat is less well emulsibed and so tends to float to the top of the mixturesos standing, and the taste is less agreeable to adowlts than is the product of the spray process. Drieg milks have become the standard method ox. artificial feeding in Great Britain. The protein curd so modified by drying that it is we assimilated even at full strength. Moreover other modifications such as the reduction or removal of fat (half-cream or skimmed dried milks respectively) may be carried out readily before mat keting. . The milk powders are so prepared that one drachm dissolved in an ounce of water re constitutes whole milk.

7. Evaporation. This consists of heating whole. milk at $180^{\circ} \mathrm{F}$. until 55 per cent. of its water hiz been lost. The product so obtained is homos genized under pressure to break up the fat globules. Evaporated milk, it is said, can only be prepared from fresh milk with a high fat content and so is a rich and reliable product. The vitamin $\mathrm{C}$ (as is also the case with dried milk) largely destroyed. The milk in sealed tins witp keep indefinitely, but without refrigeration dew teriorates rapidly when the tin is opened. Dried milk on the other hand will keep for long periods at room temperature.

For household use therefore a preservative often added to evaporated milk, namely 45 peश cent. sucrose, which increases considerably the keeping properties after the tin is opened. This 
modification is known as Sweetened Condensed milk.

Unsweetened evaporated milk is a very satisfactory infant food. The protein curd is soft and flocculent, and by simple dilution and the addition of some extra sugar feeds can be rapidly prepared. It is much used in the United States.

Sweetened condensed milk possesses far too high a carbohydrate content to be a balanced food for infants. It possesses a limited usefulness as a high calorie, low fat feeding in pathological conditions, but its low protein and rachitogenic properties make it thoroughly unsuitable for the healthy baby.

Practically all milk used in infant feeding nowadays is either boiled, evaporated, dried or acidified.

\section{Fat Reduction}

It is usual for reasons given already to feed infants for the first few weeks of life on a milk with a reduced fat content. This is achieved by using a dilution of whole milk, suitably modified, or more commonly by using a dried milk in the manufacture of which the fat content has been specifically reduced. Many infants will thrive on ' full cream' dried milk from birth, but it is found that when feeding large numbers of infants, fewer digestive disturbances result if low fat feeds are employed for the first six to eight weeks of life.

\section{Fluid and Energy Requirements}

While it is not proposed to enter here into a discussion of the practical details of infant feeding, it is necessary to discuss the optimum bulk and energy value of feeds. To maintain an infant in fluid balance it is found that a daily fluid intake of 2 to 3 fluid oz. per lb. body weight is required; the smallest infants demanding the larger figure, and the requirement lessening as the baby becomes older and heavier; $2 \frac{1}{2} \mathrm{oz}$. per lb. body weight is the generally accepted standard for the calculation of feeds for full term infants. It is found that feeding with this volume of milk feeds of which the energy value is standardized at 20 calories per oz. (which is the energy value of breast milk) maintains a satisfactory weight gain until a total daily volume of 35 to $40 \mathrm{oz}$. is being consumed. This is the upper limit of volume, and when it is reached (or often considerably earlier) the energy value of the feeds is increased by the addition of starch in the form of cereals. We can say, therefore, that if all foods are arranged to contain 20 calories per $\mathrm{oz}$., the formula ' $2 \frac{1}{2} \mathrm{Oz}$. per lb. body weight per 'day' will insure correct feeding for the first six months.

\section{Frequency of Feeds}

It is found that infants in the neonatal period cannot, in most cases, tolerate larger feeds than $3 \mathrm{oz}$. In the case of a $7-\mathrm{lb}$. baby fed at $2 \frac{1}{2} \mathrm{oz}$. per lb. this means that fewer than six feeds in the 24 hours are impractical at first, which are conveniently ordered at three hour intervals with a longer interval at night. After a few weeks the intervals can be lengthened to four hours, and the feeds reduced in number to five in the 24 hours. This longer period between feeds is in harmony with the slower gastric emptying time that we have previously described when cow's milk is being used.

\section{Gradualness}

Two cardinal rules for which theoretical grounds cannot be advanced are :-

(a) That artificial feeding should be begun with weaker mixtures than are eventually desired.

(b) That any changes in the feed should be made gradually, and only if some definite indication for a change exists.

Observance of these is essential if digestive upsets are to be avoided. During the first ten days of life the feeds should be strengthened gradually, and not until the tenth day should the expected calorie value for weight be reached.

'But let him not be glutted with the Feast, $A$ medium in the flowing meal is best.

Sometimes deny the nipple, sometimes grant

But too much watering drowns the sprouting plant.'

If these rules are followed artificial feeding will, in the majority of cases, be a painless process. The child will thrive, the mother be contented, and as for the father, 'Rest assured when he beholds the object of his soul cherishing and supporting in her arms the propitious reward of wedlock... it recalls a thousand delicate sensations to a generous mind.' 